\title{
Prognostic Factors and Complications in Patients With Operational Peptic Ulcer Perforation in Northern Thailand
}

\author{
Chutikarn Suriya $^{\mathrm{a}, \mathrm{d}}$, Nongyao Kasatpibal ${ }^{\mathrm{b}}$, Wipada Kunaviktikul ${ }^{\mathrm{b}}$, Toranee Kayee ${ }^{\mathrm{c}}$
}

\begin{abstract}
Background: Peptic ulcer perforation (PUP) is a very serious condition that leads to excessive complications and mortality. This study aimed to explore the possible prognostic factors and complications in patients with perforated peptic ulcer operation.
\end{abstract}

Methods: A 6-year retrospective cohort study in Nakornping Hospital between January 1, 2005 and December 31, 2010 was conducted. The study included 912 patients who underwent PUP surgery. Patient characteristics were analyzed by using frequency, percentage, mean (standard deviation) and median (range). A comparison between groups was made. The Pearson's Chi-squared or Fisher's exact test was used for categorical variables, as appropriate. The Student's t test was used for continuous variables with normal distribution, and Wilcoxon rank sum test was performed for continuous variables with non-normal distributions. Exponential risk regression analysis was performed to estimate the relative risk (RR) for the prognostic factors with a probability value of $<0.05$ as a statistically significant value. Post-operative length of stay was computed graphically based on Kaplan-Meier estimates.

Results: During the study period, 912 post-operative PUP patients were observed. The median age of patients was 78.5 (15 - 92) years, and $77.74 \%$ of the patients were male gender. Multivariate analysis showed that five prognostic indicators: underlying illnesses; liver disease (RR: 5.41; 95\% confidence interval (CI): 1.36 - 21.56) and kidney disease (RR: 4.72; 95\% CI: 1.05 - 21.11); duration of operation > 3 h (RR: 9.83 ; 95\% CI: 1.61-59.66); unplanned admission to ICU (RR: 9.22; 95\% CI: 1.55 - 54.68); and prolonged ventilation $>24$ h (RR: 9.02; 95\% CI: 0.42 - 9.98) were associated with postoperative PUP complications. Post-operative complications developed in 87 (9.54\%) patients with 135 complications: $11(1.21 \%)$

Manuscript accepted for publication April 18, 2013

${ }^{a}$ Clinical Epidemiology Unit, Faculty of Medicine, Chiang Mai University, Chiang Mai, Thailand

${ }^{b}$ Faculty of Nursing, Chiang Mai University, Chiang Mai, Thailand

${ }^{c}$ Department of Surgery, Nakornping Hospital, Chiang Mai, Thailand

${ }^{\mathrm{d} C}$ Corresponding author: Chutikarn Suriya, Clinical Epidemiology Unit,

Faculty of Medicine, Chiang Mai University, Chiang Mai 50200,

Thailand. Email: suriya.xunxin@gmail.com

doi: http://dx.doi.org/10.14740/gr530w patients underwent re-operation, 32 (3.51\%) patients suffered with surgical site infection, $74(8.11 \%)$ patients encountered with pneumonia and $18(1.97 \%)$ patients died. Post-operative complications including surgical site infection (incidence rate ratio (IRR): 2.00; 95\% CI: 0.76 - 5.27), re-operation (IRR: 2.65 ; 95\% CI: 0.73 - 9.62) and pneumonia (IRR: $6.97 ; 95 \% \mathrm{CI}: 6.30-7.70$ ) tend to be associated with mortality. The risk ratio showed a trend towards an increased risk for post-operative mortality with smaller values. However, this trend was not statistically significant.

Conclusions: The findings might have clinical importance as to optimize the surgical management of PUP and to minimize the complications or mortality.

Keywords: Peptic ulcer perforation; Prognostic indicator; Postoperative complications

\section{Introduction}

The peptic ulcer perforation (PUP) is a serious problem and requires surgical treatment for repair of the perforation. Postoperative PUP complications are the leading cause of mortality worldwide [1-9]. Prognostic factors which influence post-operational complications are still matters of continuing debate. In the Western, the incidence of post-operative PUP complications varies with a wide range from 0.78 to $15 \%$ $[4,5,9-13]$. In Thailand, the incidence of post-operative PUP complications was limited. Limited publication presented overall ccomplications in Siriraj Hospital, Mahidol University, Bangkok as mortality rate (9\%) and the all complications rate $(30 \%)[6]$. Because they are life-threatening, complications $[6,10-13]$ of the PUP need appropriate treatment to prevent mortality. The purpose of this study was to determine the post-operative prognostic factors and complications in patients who have operation for PUP in Northern Thailand.

\section{Materials and Methods}

A retrospective cohort study of consecutive 912 patients was 
Table 1. Patient Characteristics of Post-Operative PUP* Outcomes

\begin{tabular}{|c|c|c|c|}
\hline Patient characteristics & $\begin{array}{l}\text { Complications } \\
(\mathrm{n}=\mathbf{8 7}, 9.54 \%)\end{array}$ & $\begin{array}{l}\text { Recovered } \\
(\mathrm{n}=825,90.46 \%)\end{array}$ & $P$ value \\
\hline \multicolumn{4}{|l|}{ Gender } \\
\hline Male & $64(73.56)$ & $645(78.18)$ & 0.325 \\
\hline \multicolumn{4}{|l|}{ Age (years) } \\
\hline Median (IQR) & $78.5(15-92)$ & $66(15-87)$ & $<0.001$ \\
\hline \multicolumn{4}{|l|}{ Underlying illnesses } \\
\hline Diabetes mellitus & $11(12.64)$ & $46(5.58)$ & 0.010 \\
\hline Hypertension & $27(31.03)$ & $168(20.36)$ & 0.021 \\
\hline Lung disease & $38(43.68)$ & $64(7.76)$ & $<0.001$ \\
\hline Liver disease & $13(14.94)$ & $22(2.67)$ & $<0.001$ \\
\hline Heart disease & $33(37.93)$ & $114(13.82)$ & $<0.001$ \\
\hline Kidney disease & $20(22.99)$ & $57(6.91)$ & $<0.001$ \\
\hline Systolic blood pressure $\leq 90 \mathrm{mmHg}$ & $68(78.16)$ & $44(5.33)$ & $<0.001$ \\
\hline Referred from lower level hospitals & $60(68.97)$ & $640(77.58)$ & 0.071 \\
\hline Duration of operation $>3 \mathrm{~h}$ & $33(37.93)$ & $54(6.55)$ & $<0.001$ \\
\hline Prolonged ventilation $>24 \mathrm{~h}$ & $33(37.93)$ & $54(6.55)$ & $<0.001$ \\
\hline Unplanned admission to ICU & $70(80.46)$ & $630(76.36)$ & 0.390 \\
\hline
\end{tabular}

*PUP: peptic ulcer perforation.

conducted at a tertiary referral hospital, Nakornping Hospital in Chiang Mai. This has been served patients from connecting hospital around upper northern region Thailand between January 1, 2005 and December 31, 2010. The patients in whom histological diagnosis was confirmed as the malignant lesion in the stomach were excluded.

\section{Operation definition of variable}

Post-operative PUP complications are conditions in which the patients have developed surgical site infection, need reoperation, have pneumonia or die in hospital, certified by surgeon, based on diagnostic criteria of the Center of Disease Control and Prevention [14].

\section{Data collection}

Systematic chart review of patients with PUP was completed. This included demographic variables, history of underlying illness and clinical data. The prognostic factors and postoperative PUP complications were collected from admission to discharge.

\section{Statistical analysis}

Patient characteristics were analyzed by using frequency, percentage, mean and standard deviation. A comparison between groups was made. The Pearson's Chi-squared or Fisher's exact test was used for categorical variables, as appropriate. The continuous variables were tested for normal distribution with the Kolmogorov-Smirnov test. The Student's t test was used for continuous variables with normal distributions. Non-parametric test (Wilcoxon rank sum test) was used for continuous variables with non-normal distributions. Multivariable analysis using exponential risk regression analysis was performed to estimate the relative risk (RR) for the prognostic factors with a probability value of $<$ 0.05 as a statistically significant value. Post-operative length of stay (PLOS) was computed graphically based on KaplanMeier estimates.

\section{Results}

One thousand and twenty-six patients who underwent PUP 
Table 2. Distribution of Post-Operational Complications

\begin{tabular}{lll}
\hline Post-operational complications & $\begin{array}{l}\text { Number } \\
(\mathbf{n = 9 1 2})\end{array}$ & Percentage \\
\hline Surgical site infection & 32 & 3.51 \\
Re-operation & 11 & 1.21 \\
Pneumonia & 74 & 8.11 \\
Death & 18 & 1.97 \\
\hline
\end{tabular}

operation were considered for enrollment. Among these subjects, 37 (3.61\%) were ruled out with stomach cancer, $27(2.63 \%)$ with inflammatory lesion or lymphoma lesions and $50(4.87 \%)$ with uncompleted information. Nine hundred and twelve post-operative PUP patients were observed. The median age of patients was $72(15-92)$ years. Seven hundred and nine patients $(77.74 \%)$ were male gender. Eighty-seven patients (9.54\%) had complications. Eight hundred and twenty-five patients $(90.46 \%)$ recovered without complications. The median age of post-operative PUP patients with complication was $78.5(15-92)$ years. One hundred and forty-two patients with underlying illnesses, 68 (78.16\%) patients with systolic blood pressure $\leq 90 \mathrm{mmHg}$, $60(68.97 \%)$ patients who referred from lower level hospitals, $33(37.93 \%)$ patients who underwent duration of operation $>3 \mathrm{~h}$ with prolonged ventilation $>24 \mathrm{~h}$ and $70(80.46 \%)$ patients with unplanned admission to ICU developed complications (Table 1).

Post-operative complications developed in 87 (9.54\%) patients with 135 complications: 11 (1.21\%) patients underwent re-operation, $32(3.51 \%)$ patients suffered with surgical site infection, $74(8.11 \%)$ patients encountered with pneumonia and 18 (1.97\%) patients died. Fifty-two patients had one complication, 25 patients had two, 7 patients had three and 3 patients had suffered from four complications (Table 2).

Post-operational complications including surgical site infection (incidence rate ratio (IRR): $2.00 ; 95 \%$ confidence interval (CI): 0.76 - 5.27), re-operation (IRR: 2.65 ; 95\% CI: 0.73 - 9.62) and pneumonia (IRR: 6.97; 95\% CI: 6.30 - 7.70) tend to be associated with mortality. The risk ratio showed a trend towards an increased risk for post-operative mortality with smaller values. However, this trend was not statistically significant (Table 3).

The PLOS between patients with versus without postoperative PUP complications was a strong statistically significant linear relationship.

The patients with another complication (surgical site infection, re-operation and pneumonia) had prolonged PLOS as much as 1-31 days. On the contrary, PLOS in hospital mortality patients was very short with 1-5 days (Table 4 and Fig. 1).

Table 3. Frequency, Incidence Rate Ratio (IRR) and 95\% Confidence Interval of Associated Outcomes With Mortality Between PUP Patients With and Without Post-Operational Complications

\begin{tabular}{lllll}
\hline Associated outcomes & $\begin{array}{l}\text { Outcomes } \\
\text { presence }\end{array}$ & Mortality & IRR (95\%CI) & P value \\
\hline Surgical site infection & No & $8(44.44 \%)$ & Reference & 0.158 \\
& Yes & $10(55.56 \%)$ & $2.00(0.76-5.27)$ & 0.137 \\
Re-operation & No & $15(82.33 \%)$ & Reference & 0.958 \\
Yes & $3(16.67 \%)$ & $2.65(0.73-9.62)$ & Reference \\
& No & $0(0.00 \%)$ & $6.97(6.30-7.70)$ & \\
\hline
\end{tabular}


Table 4. Post-Operative Length of Stay (PLOS) Between PUP Patients With and Without PostOperational Complications

PLOS (days)

\begin{tabular}{|c|c|c|c|}
\hline \multirow[t]{2}{*}{ Associated outcomes } & & & \multirow[t]{2}{*}{ P value } \\
\hline & $\begin{array}{l}\text { Without complications } \\
(\mathrm{n}=825)\end{array}$ & $\begin{array}{l}\text { With complications } \\
(n=87)\end{array}$ & \\
\hline \multicolumn{4}{|l|}{ Surgical site infection } \\
\hline Median (IQR) & $7(1-29)$ & $10(7-31)$ & 0.004 \\
\hline \multicolumn{4}{|l|}{ Re-operation } \\
\hline Median (IQR) & $6(1-22)$ & $11(1-31)$ & 0.002 \\
\hline \multicolumn{4}{|l|}{ Pneumonia } \\
\hline Median (IQR) & $6(1-25)$ & $15(1-31)$ & $<0.001$ \\
\hline \multicolumn{4}{|l|}{ Death } \\
\hline Median (IQR) & $6(1-31)$ & $1(1-5)$ & $<0.001$ \\
\hline
\end{tabular}

Accordingly, multivariate analysis showed that five prognostic factors including underlying illnesses, liver disease (RR: 5.41; 95\%CI: 1.36 - 21.56) and kidney disease (RR: 4.72 ; 95\%CI: $1.05-21.11$ ), duration of operation $>3 \mathrm{~h}$
(RR: 9.83; 95\%CI: 1.61-59.66), unplanned admission to the ICU (RR: 9.22; 95\%CI: 1.55 - 54.68) and prolonged ventilation > 24 h (RR: 9.02; 95\%CI: 0.42 - 9.88) were associated with post-operative PUP complications (Table 5).

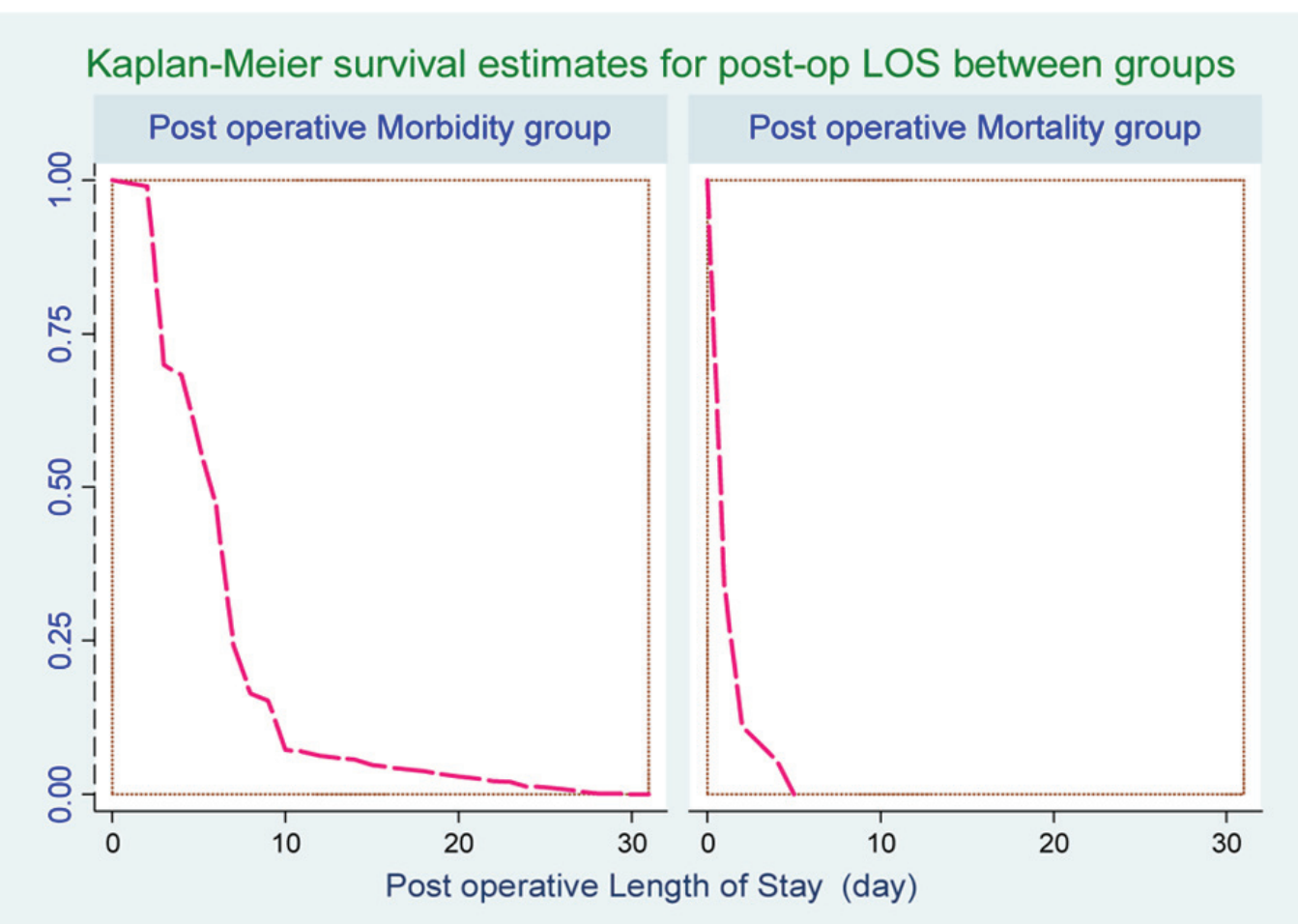

Figure 1. Survival curve for post-operative length of stay (PLOS) between groups. 
Table 5. Risk Ratio (RR) and 95\% Confidence Interval of Prognostic Factors for Post- Operative Complications

\begin{tabular}{|c|c|c|c|}
\hline Prognostic factors & Multivariable RR & $95 \% \mathrm{CI}$ & Pvalue \\
\hline \multicolumn{4}{|l|}{ Gender } \\
\hline Male & 0.35 & $0.06-1.96$ & 0.235 \\
\hline \multicolumn{4}{|l|}{ Age (years) } \\
\hline$\geq 60$ & 0.11 & $0.013-0.84$ & 0.034 \\
\hline \multicolumn{4}{|l|}{ Underlining illnesses } \\
\hline Diabetes mellitus & 2.15 & $0.53-8.73$ & 0.281 \\
\hline Diabetes mellitus & 1.12 & $0.34-3.74$ & 0.851 \\
\hline Lung disease & 1.33 & $0.29-6.05$ & 0.715 \\
\hline Liver disease & 5.41 & $1.36-21.56$ & 0.015 \\
\hline Heart disease & 1.23 & $0.28-5.29$ & 0.784 \\
\hline Kidney disease & 4.72 & $1.05-21.11$ & 0.042 \\
\hline Systolic blood pressure $\leq 90 \mathrm{mmHg}$ & 2.42 & $0.30-19.41$ & 0.407 \\
\hline Duodenal ulcer perforation & 3.52 & $0.31-40.50$ & 0.313 \\
\hline Elective surgery & 2.02 & $0.42-9.88$ & 0.383 \\
\hline Duration of perforation $>3 \mathrm{~h}$ & 9.83 & $1.61-59.66$ & 0.013 \\
\hline Referred from lower level hospitals & 0.97 & $0.18-5.10$ & 0.969 \\
\hline Unplanned admission to ICU & 9.22 & $1.55-54.68$ & 0.014 \\
\hline Prolonged ventilation $>24 \mathrm{~h}$ & 9.02 & $0.42-9.88$ & 0.038 \\
\hline
\end{tabular}

\section{Discussion}

Patients with PUP had diffused from floods of the peritoneum with the acid contents of the stomach with more widespread spillage. This is a serious condition with acute inflammatory peritoneal reaction and trend to peritonitis when they were delayingly detected [15]. The decision-making of clinicians will be concerned with management outcome assisted by treatment guidelines. The surgical treatment is one of management in PUP patient.

In this study, five prognostic factors related to postoperative complications are underlying illnesses (liver and kidney disease), duration of operation $>3 \mathrm{~h}$, unplanned admission to the ICU and prolonged ventilation $>24 \mathrm{~h}$. These supported previous studies, factors associated with morbidity $[4,16-19]$ and some studies presented factors increased mortality after surgical treatment $[1,2]$.

The underlying illnesses (liver and kidney disease) in PUP patients are associated with morbidity because hepatic and renal functions are interconnected through both the existence of related primary organ and hemodynamic interre- lationships. Renal and liver diseases caused renal and liver dysfunction. However, the presence and duration of renal and liver diseases before operation increase in association with prolonged operation time. They are risks of vascular and muscle necrosis with consequent renal failure and multiple organs failure. Multiple organs failure was identification of underlying pathogenic mechanisms and possible mediators of specific organ system failures, so that unplanned admission to the ICU therapy may be directed at the initial post-operative complications $[15,20]$.

The post-operative complications in PUP patients in this study included re-operation, surgical site infection, pneumonia and death during hospitalization. The result supports previous studies that morbidity and mortality rates of any complication of ulcer disease are around 10 to $15 \%[15,20]$.

PLOS in patients with hospital mortality was shorter than morbidity group, within 1-5 days. They were admitted with severity conditions. It can be considered a main indicator of patients' post-operative complications as a clinical indicator from the operating care and has been thought to reflect the quality of care. 


\section{Study strengths}

The strengths of the study were able to include a large number of patients. Furthermore, we were able to include all patients admitted with PUP who underwent open surgery.

\section{Study weakness}

A limitation on this study was retrospectively reviewed database of medical information. As the data were reported previously, so they might be not in high novelty; in addition, the analysis of occurrence of post-operative complications was based on only surgeon's decision, so multi-disciplinary would be granted.

\section{Conclusion}

The protocols to reduce complications in PUP patients might be developed, which could classify patients into critical and non-critical groups. However, patients in critical group should be required urgent clinically suitable.

\section{Acknowledgement}

The authors wish to acknowledge the director of Nakornping Hospital for his kind support.

\section{Ethical Approval}

The project approved under Director of Nakornping Hospital and Committee for Research in Human Subjects Protection from Faculty of Medicine, Chiang Mai University.

\section{Conflicts of Interest}

The authors have none to declare in this study.

\section{References}

1. Adams TD, Gress RE, Smith SC, Halverson RC, Simper SC, Rosamond WD, Lamonte MJ, et al. Long-term mortality after gastric bypass surgery. N Engl J Med. 2007;357(8):753-761.

2. Arenal JJ, Bengoechea-Beeby M. Mortality associated with emergency abdominal surgery in the elderly. Can J Surg. 2003;46(2):111-116.

3. Barut I, Tarhan OR, Cerci C, Karaguzel N, Akdeniz Y, Bulbul M. Prognostic factors of peptic ulcer perforation. Saudi Med J. 2005;26(8):1255-1259.
4. Bin-Taleb AK, Razzaq RA, Al-Kathiri ZO. Management of perforated peptic ulcer in patients at a teaching hospital. Saudi Med J. 2008;29(2):245-250.

5. Di Carlo I, Toro A, Sparatore F, Primo S, Barbagallo F, Di Blasi M. Emergency gastric ulcer complications in elderly. Factors affecting the morbidity and mortality in relation to therapeutic approaches. Minerva Chir. 2006;61(4):325-332.

6. Lohsiriwat V, Prapasrivorakul S, Lohsiriwat D. Perforated peptic ulcer: clinical presentation, surgical outcomes, and the accuracy of the Boey scoring system in predicting postoperative morbidity and mortality. World J Surg. 2009;33(1):80-85.

7. Ersumo T, Y WM, Kotisso B. Perforated peptic ulcer in Tikur Anbessa Hospital: a review of 74 cases. Ethiop Med J. 2005;43(1):9-13.

8. Behrman SW. Management of complicated peptic ulcer disease. Arch Surg. 2005;140(2):201-208.

9. Makela JT, Kiviniemi H, Ohtonen P, Laitinen SO. Factors that predict morbidity and mortality in patients with perforated peptic ulcers. Eur J Surg. 2002;168(8-9):446451.

10. Rahman MM, Islam MS, Flora S, Akhter SF, Hossain S, Karim F. Mortality in perforated peptic ulcer patients after selective management of stratified poor risk cases. World J Surg. 2007;31(12):2341-2344; discussion 23452346.

11. Rajesh V, Chandra SS, Smile SR. Risk factors predicting operative mortality in perforated peptic ulcer disease. Trop Gastroenterol. 2003;24(3):148-150.

12. Taha AS, Angerson WJ, Prasad R, McCloskey C, Gilmour D, Morran CG. Clinical trial: the incidence and early mortality after peptic ulcer perforation, and the use of low-dose aspirin and nonsteroidal anti-inflammatory drugs. Aliment Pharmacol Ther. 2008;28(7):878-885.

13. Thomsen RW, Riis A, Christensen S, Norgaard M, Sorensen HT. Diabetes and 30-day mortality from peptic ulcer bleeding and perforation: a Danish populationbased cohort study. Diabetes Care. 2006;29(4):805-810.

14. Mangram AJ, Horan TC, Pearson ML, Silver LC, Jarvis WR. Guideline for prevention of surgical site infection, 1999. Hospital Infection Control Practices Advisory Committee. Infect Control Hosp Epidemiol. 1999;20(4):250-278; quiz 279-280.

15. Stenhouse C, Coates S, Tivey M, Allsop P, Parker T. Prospective evaluation of a modified Early Warning Score to aid earlier detection of patients developing critical illness on a surgical ward. Br J Anaesth. 2000;84:663..

16. Kujath P, Schwandner O, Bruch HP. Morbidity and mortality of perforated peptic gastroduodenal ulcer following emergency surgery. Langenbecks Arch Surg. 2002;387(7-8):298-302.

17. Moller MH, Adamsen S, Thomsen RW, Moller AM. Preoperative prognostic factors for mortality in peptic ulcer 
perforation: a systematic review. Scand J Gastroenterol. 2010;45(7-8):785-805.

18. Stoltzing H, Emmel J, Thon KP. Surgical decisions in stomach perforation. Viszeralchirurgie. 2007;42(1):513.

19. Uccheddu A, Floris G, Altana ML, Pisanu A, Cois A,
Farci SL. Surgery for perforated peptic ulcer in the elderly. Evaluation of factors influencing prognosis. Hepatogastroenterology. 2003;50(54):1956-1958.

20. Kreissler-Haag D, Schilling MK, Maurer CA. [Surgery of complicated gastroduodenal ulcers: outcome at the millennium]. Zentralbl Chir. 2002;127(12):1078-1082. 